\title{
The Application of Ethical Interpretation of Shaanxi Local Novels in English Translation Teaching*
}

\author{
Xiaohui Zhang \\ Xi’an Fanyi University \\ Xi'an, China
}

\begin{abstract}
Under the new situation, the implementation of the "One Belt and One Road" and the "going out" strategy have enabled Shaanxi literature to produce a vigorous vitality. In 2011, the English-language overseas promotion program compiled the English version of the "Shaanxi Writer Short Film Novel Collection". In the process of introducing these literary works, the translation organization of the authorities, the translator, the translation strategy adopted by the translator, and the publisher of the translation all have an impact on the choice of words, the quality of the translation, and the distribution scope. All of these respects belong to the category of translation ethics research. Exploring these translation processes and combining them with English translation teaching to improve teaching theory research, and cultivate more practical translation talents have an important role in the development of the translation industry. Therefore, this article is guided by the translation ethics theory, through the analysis of the current situation of English translation teaching, combined with the translation ethics theory to guide translation teaching activities. Taking Gao Jianqun's "Six Six Towns" and English version as the research object, analyzing the translator's translation strategy and applying it to the translation classroom to improve the quality of translation teaching.
\end{abstract}

Keywords-translation ethics; English translation teaching; English version of "Six Six Towns"

\section{INTRODUCTION}

With the deepening of China's reform and opening up, General Secretary Xi Jinping proposed to implement the "four comprehensive" strategic layout and five development concepts, and implement the decision-making deployment and fresh practice of "catching over and exceeding and transforming development". The Shaanxi literary community has also combined its local characteristics to highlight the theme of "One Belt and One Road" to expand the cultural outreach and implement the "going out" strategy of literature, the Shaanxi Foreign Translation and Promotion Program (SLOT), and the English version of "Shaanxi Writer Short Stories" is published in such an atmosphere. This is the first collection of collective translation works by writers in the province. In addition, on August 23, 2017, as an important measure to help Chinese culture "going out", on the day of the 24th Beijing International Book Fair, the English version of Shaanxi writer Jia Pingwa's "Gaoxing” Happy Dreams was

*Project title: The Application of Ethical Interpretation of Shaanxi Local Novels in English Translation Teaching

Project No.: SGH17H482. synchronized globally at 14 Amazon sites.

At the same time, Jia Pingwa also lamented that in the process of translation and publication of these literary works, the organization of the government, the choice of the translator, the professionalism of the translator itself, the publisher of the translation, the sponsor, etc. all have the influence on the choice of translation text and the quality of translation, and even on the distribution scope of the translated works. Therefore, using the correct translation theory to introduce the actual translation activities into the translation classroom for analysis is helpful to improve the quality of translation teaching, cultivate high-quality translation talents, improve the quality of translation works, and purify the translation environment.

\section{TRANSLATION ETHICS THEORY AND TRANSLATION TEACHING}

Foreign research on translation ethics first appeared in 1984, and the French translation theorist Antonona Berman pioneered the concept of "translation ethics". Later, scholars represented by Anthony Pim and Lawrence Venuti used translation ethics to study different fields. However, it is rare to introduce local characteristic culture into the classroom field. The main reason is that the local characteristic culture is not paid enough attention.

The domestic study of translation theory has translated the representative translation ethics of the West. Lu Jun proposed to introduce Habermas's theory of communicative action into the study of translation, making translation ethics "an integral part and research content of translation studies." Xu Jun pointed out in the article "On the Three Levels of Translation Activities", "If we carefully examine the whole process of translation activities, we can see the choice of translation objects, the adoption of translation methods, including the compilation of translation works, are all influenced by the ethical constraints 'how to translate'." Xu Jun thoughts that every responsible translator must seriously consider and strictly address the issues raised by the three dimensions of "willingness", "reality" and "morality".

At present, there are many problems in the current situation of translation teaching and practice. First, the students' attitude towards translation theory is not correct enough, and they are upset. They always feel that they can understand the original text and can use this dictionary to translate. Second, the impact of teachers' teaching. At present, 
translation education has been utilitarian, teachers only pay attention to the teaching of book knowledge, making translation theory and practice seriously separated, translation theory is seriously lagging behind, and practice is too oldfashioned to keep up with the development of society. Third, a large number of various supplementary materials and literary translations on the market are inferior products, which seriously affects the learning process of translation learners.

In summary, there are many studies on translation teaching, but few scholars interpret the study of English translation teaching from the perspective of Shaanxi local literature, and the empirical research on English translation teaching from the perspective of translation ethics is even rare. Since the 1990s, Spivak's translation ethics against the colonial culture of imperialism has raised the awareness of the protection of national culture by researchers from all over the world, and has promoted the development and promotion of local culture in Shaanxi. Under the guidance of the translation ethics theory, the author takes the English version of the novel "Six Six Town" by Shaanxi representative writer Gao Jianqun as an example to conduct an empirical study on the English translation teaching mode.

Translation ethics is a moral or ethical study related to translation activities, translation studies, translation criticism, translation teaching, etc., that is, examining all aspects of translation from an ethical perspective. Therefore, translation ethics mainly includes the acceptance and dissemination of "translator ethics", "intermediary ethics" and "reader ethics" and translations. In the translation teaching, using advanced translation ethics theory as a guide, combined with the English version of the "Six Six Town" in Shaanxi, the translator's choice of the work is analyzed in the classroom practice of translation. Does the translator follow the translator's ethics? That is, the translator's motivation for translation and the purpose of the novel's text selection, and whether the translation process is faithful to the original, what translation methods and strategies are used; the middleman is the organization sponsor of the translation activity, which has influence on the distribution scope of translation text. At the same time, the practitioners in the translation classroom are both readers of the novel and translators of the novel. Their understanding of the novel and their views on the original novel and the translation have become the issues discussed in the translation classroom. Therefore, the application of translation ethics theory to the classroom, combined with the actual analysis of the "Six Six Town" novel, plays an important role in improving translation teaching.

\section{RESEARCH ON ENGLISH TRANSLATION TEACHING MODEL FROM THE PERSPECTIVE OF TRANSLATION ETHICS} THEORY

The author divides the translation teaching class into two, one is taught by the traditional translation teaching mode, the other is the contrast class, guided by translation ethics, and students are clearly told that the translation class is divided into three parts: The translator ethics, middleman ethics and reader ethics. After one month, the translation teaching method under the guidance of translation ethics was tracked through questionnaires and personal interviews. The following are examples of students in the teaching process:

\section{A. The Translator Ethics}

1) The selection of the translator: First of all, the translator of "Six Six Towns" is Wang Hongyin, a professor, a doctoral tutor, deputy director of the Translation Research Center at the School of Foreign Languages of Nankai University in Tianjin, a member of the College English Teaching Guidance Subcommittee of the Ministry of Education, and a member of National Translation Master's Degree (MTI) Education Instructor Committee, President of the Chinese Cultural Classics Translation Research Association, Vice President of the Chinese English-Chinese Comparative Research Association, and Executive Director of the China Intercultural Communication Society. He was mainly engaged in translation teaching and research, concentrating on translation theory research, and has made great achievements and contributions to the construction of translation theory in China. He worked on scientific and technical translation in Xi'an in the early years. He used to be a tour guide and academic interpreter. He also had profound knowledge in literature, linguistics, Chinese and Western philosophy, aesthetics, psychology and other fields. In addition, he loves painting, calligraphy, music, and has translated texts in poetry, painting, calligraphy, and Qin scripts. These experiences have laid a solid foundation for his translation teaching and translation theory research.

2) Translator's translation motivation and selection of novel texts: Class 1: Gao Jianqun's "Six Six Towns" (excerpt) novels are included in the English version of "Shaanxi Writers' Short Stories Collection". The publication of this novel collection was initiated by the Shaanxi Literature Overseas Translation Promotion Program, translated by the relevant workers in Shaanxi Provincial Writers Association and Shaanxi Province.

Class 2: Gao Jianqun's "Six Six Towns" (excerpt) novels are included in the English version of "Shaanxi Writers' Short Stories Collection". The publication of this novel collection was initiated by the Shaanxi Literature Overseas Translation Promotion Program, translated by the relevant workers in Shaanxi Provincial Writers Association and Shaanxi Province. Although organized by the above two units, the freedom to choose a text lies in the translator himself. The reasons why the translator chooses "Six Six Towns" as the original translation are as follows: First, many scholars in the study of Shaanxi literature have basically studied the works of Chen Zhongshi, Jia Pingwa and Lu Yao with certain influence. Gao Jianqun is also an influential writer in Shaanxi, but there is still a lack of research on his works. Second, Zhang Jiashan, the protagonist of "Six Six Towns", is an ordinary peasant in northern Shaanxi. His "heroism" and the thought to save society in his heart is a typical image and dialogue between the era and the environment; and this spirit is in line with the theme of "Chinese Dream" that carries forward the tradition and reform and innovation. Third, the author Gao Jianqun was born in 1954, "Six Six Towns" was written during the period 
of his post in Huangling County, Shaanxi Province, it is a novel that described the "Knight Spirit" of the ordinary people in the west followed the "The Last Hsiung-nu". The translator is Wang Hongyin, the professor and the doctoral supervisor of the School of Foreign Languages of Nankai University. Professor Wang Hongyin, who was born in the same period (1953) with Gao Jianqun, was born in Huayin, Shaanxi. Therefore, some of the ideas in the original text have a certain level of overlap with the translator himself.

Analysis: Teachers use the theory of translation ethics to guide students before translation. Students in Class 2 have deeper understanding on the author of the novel, the motivation of translation and why the novel is chosen to translate than students in Class 1, which lays a more solid foundation for the translation process.

\section{B. Translation Process}

The translation process here contains two levels of meaning: first, analyze the translation strategy adopted by the translator in the English translation of "Six Six Towns"; second, the teacher organizes students to translate some wonderful passages in "Six Six Towns" and makes a comparison between the two classes. Through such a process of learning and translation practice, students can experience the translator's ethics, the adoption of translation strategies and translation practice.

(1) My experience is this: look at her hips and legs first, and then her waist and lips. Mr. Zhang is no whistle-blower, but judging from her way of walking, I'd bet that city woman is no maiden!"

Analysis: This sentence has many verbs in the original Chinese text, basically all short sentences, arranged in a logical relationship. On the basis of rationalizing the relationship, the translator adds connection means, such as then, but, and at the same time, according to the context correlation, the missing part of the Chinese is added to the translation: Her hips and legs, her waist and lips, making the translation clear and accurate.

Class 1: How to judge a woman is maiden or not, I have some experience, that is: first look at her hips and legs, and then waist and lips. I'm not blowing, and I'd bet that woman is not a maiden from her way of walk.

Class 2: My experience is: look at her hips and legs first, and then her waist and lips. I'm not a whistle-blower, but I'd bet that woman is no longer a maiden from her way of walk.

Comments: Before the translation practice, the teacher analyzed the original text in Class 2 in addition to the traditional translation strategy: this is a remote mountain town. According to the novel background, the villagers' cultural level is not high. Words should be adopted in a more simplistic and life-like manner, and attention should be paid to the frequent use of nouns rather than verbs in English. The translation of students in Class 1 lacks the reorganization of the sentence order, and is slightly formal. That of students in Class 2 pays attention to the choice of nouns and the order of the sentences.

(2) A child's face suddenly appears from under the table.
Startled, Duckweed Nan opens her eyes instantly.

The child gazes at her and mumbles, "legs in flood, lips in blood!"

Analysis: The translation follows the paragraph pattern in the original text and the overall consciousness of the group, using the double preposition form to accurately express the child's position. According to the expression habits of English the sequence of the adjective startled used in the second sentence was adjusted. The translation does not use the Chinese Pinyin to translate the name of the woman. Instead, it uses Duckweed Nan. Duckweed is a kind of plant in English, an aquatic fern. It is used in Chinese to metaphor that people are drifting from place to place because duckweed has no roots. Although Nan Xiuping in the original text has achieved great success, but she has not found her own child, her heart is not settled. Moreover, the translation here and the name of her child's car are also a reflection. The third sentence is a dialect, which means muttering. The word mumble is very appropriate, and the translator uses the fishing legs and drinks the mouth of the blood with head rhyme and the ending rhyme according to the original text, so the translation here is very successful.

Class 1: Suddenly, a child's face appears from under the table. Nan Xiuping was astonished with her eyes open widely. The child gazes at Nan and mumbles, "legs in pants, mouth in blood!"

Class 2: A child's face appears suddenly from under the table. Shocked, Nan opens her eyes widely. The child gazes at Nan and mumbles, "legs in pants, lips in blood!"

Comments: Before students in Class 2 carried out the translation practice, the teacher focused on the translator's ethics, that is, correctly understanding the original author's expression and making full use of the rhetorical techniques. The translation of students in Class 2 placed the suddenly in the middle because the original author did not want to highlight the sudden, but the child, who was later confirmed to be the granddaughter of Nan Xiuping, and finally followed Nan Xiuping to Beijing to study and live. For "legs in pants, lips in blood", although the head rhyme and the ending rhyme are not used as the translation, the teacher has already had the awareness of using rhetoric.

(3) "Pillar, I have been talking to your wife about something quite serious, and now that you are here, I'll tell you."

"Don't bother, Uncle Zhang. I know all about it - about Duckweed."

"You know?" Zhang is caught off guard by this new development.

Analysis: The above three sentences have adopted the method of addition. What does not express exactly in the first sentence of the original Chinese text, the translator adds quite serious in the translation, which enhances the coherence of the context and makes the translation more specific. What referred in the second sentence in the original Chinese text, covered in the context, is the child of Xiu Ping, the translator adds "about duckweed", because Zhuzi is a new character, 
and the addition makes the character rounder, and fully reflect that Zhuzi is clear to the question of Zhang Jiashan.

Class 1: "Zhuzi, I've told your wife about a matter. Now that you have come back, I want to talk about it to you once more." "It's about Xiuping, isn't it? I know all about it!" "You know?" Zhang is astonished.

Class 2: "Zhuzi, I have been talking to your wife about an important matter. Now that you have come back, I'll tell you." "I know it's about Xiuping. I know all about it!" "You know?" Hearing this, Zhang is astonished.

Comments: The teacher repeatedly emphasizes the translator's ethics in Class 2, that is, to try to figure out the original text; the anti-sense interrogative sentence is used in translations of students in Class 1. Usually the sentence is used when the speaker is uncertain about the things, while Zhuzi is clear to Xiuping's child in original text, which does not conform to the meaning of the original text. In the last sentence, students in Class 2 adopted the participle construction. Although it was not as accurate as the original translation, it not only enriched the sentence structure, but also expressed the surprise process after Zhang Jiashan heard it.

Of course, there are also several parts of the translation that differ from the original expression:

(1) 'Simply 'Plantain.' Then, Plantain, I need your help. Would you go and ask Hillock Zhang to come over to my room in the evening? Just tell him that my name is Duckweed Nan. I am an educated young woman from Beijing, settling down in this brigade outpost."

Analysis: "Educated Youth" is the unique name of the young students in China in the 1960s who experienced from urban to rural areas. An educated young woman could not accurately express the social situation at the time.

Class 1: "Cheqian, would you please help me? Would you go to Uncle Zhang's office and ask him to come here this evening? Just tell him I am Nan Xiuping, an educated young woman from Beijing in the 1960's!"

Class 2: "Cheqian, I need your help. Would you go to Uncle Zhang's office and ask him to come here this evening? Just tell him I am Nan Xiuping, an educated young woman from Beijing (urban high school graduates who went to work and settle in the rural areas in response to the call of Man Zedong during the Cultural Revolution)

Comments: The translator should stand on the doublesided perspective of the original author and the reader, and convey the original meaning as accurately as possible to follow the translator's ethics to the maximum extent. The teacher guides students to use the interpretation method to supplement Nan Xiuping's past in terms of "Educated Youth" in special era, and also better help readers understand why Nan Xiuping gave up her children in the special social and historical background.

(2) Duckweed holds a video recorder in her hand, with its small bag hanging from her shoulder.
Analysis: The word in original text is Portmonee, not a package with a miniature camera, and the translation is a camera pack of Nan Xiuping.

Class 1: Nan Xiuping hung a bag with a video recorder in her hand.

Class 2: Nan Xiuping hung a purse around her shoulder, a video recorder in one hand.

Comments: There is nothing wrong with the translation of students in Class 1, but the translation style is not in line with the characteristics of the novel. According to the original text, Nan Xiuping is a successful business woman. The selection of words about her bag should also be noted. The students in Class 2 use "purse" under the guidance of the teacher with the independent subject deconstruction to make the translation sentence more diversified.

(3) She leads the way down. Before them a date tree stand tall, and Duckweed takes some pictures of it for a while, then she takes a picture of the village between the woods and the hills in the distance.

Analysis: The original text explained that Nan Xiuping is carrying a camera, but the students translated into taking photos.

Class 1: Nan Xiuping shoots the date tree for a while, then shoots the village between the woods and the hills.

Class 2: Nan Xiuping shoots the date tree for a while, then the village between the woods and the hills.

Comments: Nan Xiuping did two same actions, so we can use the provincial translation method here.

\section{Middleman Ethics}

The internal control factor of the translation is the translator. The external control factor is the sponsor. The sponsor can be individuals, groups, religions, communities, political parties, social classes, publishers, media, etc., that is, people who influence or control the translation. These intermediaries are not directly involved in translation. The collection of novels including "Six Six Towns" is organized by the Shaanxi Writers Association and the Shaanxi Translation Association. The selection of translators is determined by these two organizations. At the same time, the organizers also invited overseas publishing experts to select their works, listen to suggestions and opinions such as Robert Farnsworth, Mary Warpeha, and judge the tastes and reading tendencies of overseas readers from the perspective of overseas literary market.

\section{The Role in Translation Teaching}

From the above-mentioned translation ethics theory, the analysis of the English translation of "Six Six Towns" and the comparison of experimental teaching class translation practice, we can easily find that: First, in addition to the explanation of translation theory in the classroom, if the teacher can combine translate theory with the translation practice, it can appropriately avoid the impetuous psychology of students and allow students to truly calm down and translate, which promotes the improvement of the quality of translation 
teaching. Second, the combination of translation theory and current practice avoids laggard theory and stereotypical practice, making the theory closely related to the development of contemporary society. Third, the improvement of students' translation ability also cultivates more capable translators for the market, thus improving the quality of translation and clearing the translation market.

\section{CONCLUSION}

Inspired by translation ethics, the author explores a new approach to English translation classrooms based on this theory. In this paper, the author summarizes the theory of translation ethics firstly. Secondly, he discusses the problems in the current English translation teaching. Then, in the English translation teaching, in addition to teaching translation theory, we should combine with local characteristics, join the translation analysis and practice of "Six Six Town", so that translation theory and translation practice are organically combined. Let students experience and strengthen the use of translation theory in translation practice, thus improving the quality of translation teaching and improving students' translation ability. Of course, this paper also has its limitations. Because of the lack of foreign students, we can't test the quality of translation from the perspective of foreign readers' ethics. In short, this is a new attempt for English translation teaching, but the development of translation teaching still requires many teachers' research and bold attempts. At the same time, it also requires the cooperation of students and the translation market to better improve translation teaching and clear the translation market.

\section{REFERENCES}

[1] Old Land New Tales: 20 Best Stories of Shaanxi Writers. [M] Beijing: China Intercontinental Press, 2011

[2] Peng Ping. Translation Ethics [M] .Beijing: Central Compilation \& Translation Press, 2013

[3] Bai Jie. A Study of the English Version of "Blood Breasts and Buttocks" in the Perspective of Chesterman's Translation Ethics Model [D] China Master's Theses Full-text Database, 2015

[4] Wu Jie. A Research on Literary Language in 'The Ordinary World'[D]. China Master's Theses Full-text Database, 2013 